University of Wollongong

Research Online

Faculty of Law, Humanities and the Arts Papers (Archive)

Faculty of Arts, Social Sciences \& Humanities

$1-1-2014$

In search of ontological emergence: diachronic, but non-supervenient

Michael D. Kirchhoff

Macquarie University, kirchhof@uow.edu.au

Follow this and additional works at: https://ro.uow.edu.au/lhapapers

Part of the Arts and Humanities Commons, and the Law Commons

Research Online is the open access institutional repository for the University of Wollongong. For further information contact the UOW Library: research-pubs@uow.edu.au 


\title{
In search of ontological emergence: diachronic, but non-supervenient
}

\author{
Abstract \\ Most philosophical accounts of emergence are based on supervenience, with supervenience being an \\ ontologically synchronic relation of determination. This conception of emergence as a relation of \\ supervenience, I will argue, is unable to make sense of the kinds of emergence that are widespread in \\ self-organizing and nonlinear dynamical systems, including distributed cognitive systems. In these \\ dynamical systems, an emergent property is ontological (i.e., the causal capacities of $P$, where $P$ is an \\ emergent feature, are not reducible to causal capacities of the parts, and may exert a top-down causal \\ influence on the parts of the system) and diachronic (i.e., the relata of emergence are temporally \\ extended, and $\mathrm{P}$ emerges as a result of some dynamical lower-level processes that unfold in real time). \\ Keywords \\ search, emergence, diachronic, but, non, supervenient, ontological \\ Disciplines \\ Arts and Humanities | Law \\ Publication Details \\ Kirchhoff, M. (2014). In search of ontological emergence: diachronic, but non-supervenient. Axiomathes, \\ 24 (1), 89-116.
}




\section{Title page:}

Name of author: Michael D. Kirchhoff

Title: In Search of Ontological Emergence: Diachronic, but Non-Supervenient

Article type: Original research

Affiliation: Macquarie

University Department of

Philosophy Sydney

Australia

\section{Contact details:}

Telephone: 0404770574

Email: michael.kirchhoff@students.mq.edu.au 


\section{Introduction}

The conception of "emergence" is very much a philosophical term of art; it can mean, as Jaegwon Kim mentions, pretty much what you want it to mean, "the only condition being that you had better be reasonably clear about what you mean, and that your concepts turn out to be something interesting and theoretically useful." (2006, p. 548) Indeed, the debate about emergence is crowded with multifarious and vague claims - such as "the whole is more than the sum of its parts" (cf. Silberstein \& McGeever 1999). Fortunately for us, we do not have to start from scratch when we begin to reflect on how best to understand the notion of emergence. For example, there are signposts like the following from Mitchell, who highlights that: "The key features of emergence for both philosophical treatments and scientific applications are novelty, unpredictability and the causal efficacy of emergent properties or structures, sometimes referred to as downward causation [or, "circular causation" in dynamical systems theory (Kelso 1995, p. 9)].” (2012, p. 173)

This passage gives us an initial fix on the issue of emergence, since it expresses three different interpretations of what is at stake in the discussion concerning emergence: one epistemological; and two different species of ontological emergence. In the case of epistemological emergence, emergent phenomena are conceived of as unexplainable or unpredictable prior to modeling. Epistemologically emergent phenomena are cases in which it is often hopeless (if not impossible) to understand emergent features of the whole or the behavior of the whole by tracing only the individual parts or processes making up the whole. Often, as Silberstein \& McGeever point out, in these cases "we must find a method of representing what the system does on the whole or on average in a manner which abstracts away from causal detail.” (1999, p. 185) Prima facie, at least, dynamical systems theory is a paradigm discipline in which the study of qualitative behavior of higher-level phenomena is dependent on simulation/modeling. There are at least two possible meanings of ontological emergence. The first is that a system S, say, has emergent features, Ps, that are not reducible to the component parts that make up S, or that are not determined by the base or lower-level causal processes. As such, the Ps in S may be said to "possess causal capacities not reducible to any of the intrinsic causal capacities of the parts nor to any of the (reducible) relations between the parts." (Silberstein \& McGeever 1999, p. 182) The second meaning of ontological emergence is that emergent features, Ps, are features of a system, S, that possess causal capacities not reducible to the parts that make of $S$, and where the Ps in question exert a 
causal influence on the parts of the system "consistent with, but distinct from, the causal capacities of the parts themselves." (Silberstein \& McGeever 1999, p. 182) Ontological emergence, especially in its second formulation, is the most radical of the three species of emergence, yet several philosophers have recently argued that ontological emergence, with downward causation, is ubiquitous in nature - e.g., in far-from-equilibrium dynamical systems (Boogerd et al. 2005; Campbell \& Bickhard 2011; Mitchell 2012; Silberstein 2012; and Silberstein \& McGeever 1999).

1.1. Metaphysical building-relations and diachronic vs. synchronic

Before setting up the arguments that I shall develop in this paper, we need to clarify a few conceptual issues. In the search for ontological emergence that is diachronic, yet not a supervenience relation (note that the standard view of emergence presupposes that emergent features supervene on an "emergence base," thus construing emergence as a species of supervenience), the first thing we need to understand is the idea of a metaphysical building-relation. In her (2011) article, "Construction area (no hard hat required)," Bennett begins by specifying that a variety of relations widely used by philosophers - such as constitution, composition, realization, supervenience, emergence, and many others - are species of socalled meta physical building relations. By "building-relation," Bennett intends to capture what the idea of something being built up from or generated from or giving rise to or getting out of implies. A few familiar examples of this idea: how do non-relational properties give rise to relational properties? How are higher-level features generated from lower-level ones, and what is the relation between them?

Unlike diachronic emergence, metaphysical building-relations such as supervenience are usually considered to hold synchronically (note that insofar as emergence is based on supervenience, as it is assumed in the standard view, emergence equally holds synchronically). But what does "diachronic" as well as "synchronic" mean in this context? The central reason for conceiving of supervenience in terms of synchronicity is nicely captured by Bennett: "Building relations do not unfold over time. [If property Q supervenes on $\mathrm{P}$, it does so at some time t]; [...]; if these time slices compose that persisting object, they do so simpliciter. Causation, in contrast, is paradigmatically diachronic, and that idea is frequently invoked to distinguish causation from relations like composition, constitution, or supervenience [...]." (2011, pp. 93-94; italics in original) That is to say, if Q supervenes on an event, state or process P, Q exists where and when P exists. Hence, for some event, state or process Q, if P takes place prior to Q's 
occurrence, or if $\mathrm{P}$ takes place apart from Q's occurrence, then Q does not supervene on $\mathrm{P}$ (see also Shapiro 2011). Thus, if a metaphysical building-relation holds synchronically, the relation between $Q$ and P, say, must hold instantaneously and Q cannot be the result of a temporally unfolding process, if the relation between $\mathrm{Q}$ and $\mathrm{P}$ is to qualify as a metaphysical building-relation. In contrast to synchronic building relations, if a building-relation is diachronic, which is the case for diachronic emergence, then the emergent feature, as Silberstein puts it, "emerges as, at least in part, a function of some dynamical lower-level or more basic process that unfolds in time. As the system evolves in time new 'higherlevel' properties will come into being as a [result] of the unfolding of the more fundamental dynamical process[es]." (2012, p. 630)

But can we say more than this? In the case of supervenience and emergence, since both relations are (or can be said to be) metaphysical relations, the distinction between "synchronic" and "diachronic" must equally pick out something of ontological significance. To get a fix on this, consider the split between what I call "ontological synchronicity," on the one hand, and "ontological diachronicity," on the other. The supervenience relation between $\mathrm{Q}$ and $\mathrm{P}$, say, is ontologically synchronic, in the sense that $\mathrm{Q}$ supervenes on $\mathrm{P}$ at every moment at which it exists, viz., that $\mathrm{Q}$ supervenes on the intrinsic states of $\mathrm{P}$, where the intrinsic states of $\mathrm{P}$ are intrinsic to a particular time interval, as opposed to being spread or extended across a number of time intervals. On the account provided by Hofweber \& Velleman, on the so-called endurance-perdurance distinction, we can capture what it implies for $\mathrm{Q}$ to supervene on $\mathrm{P}$ ontologically synchronic. As Hofweber \& Velleman specify: "the [elements that] are intrinsic to a time have to determine the identity of the object in order for its identity to be fully determined at that time." (2010, p. 16) Now, contrast ontological synchronicity with ontological diachronicity. In emergence, if the relation between lower-level processes, $\mathrm{Xs}$, and the higher-level emergent feature, $\mathrm{Y}$, is diachronic (ontologically), then the relation of emergence is not ontologically synchronic - that is, it is not present in its entirety within a single time slice. In cases of diachronic emergence, the relata are commonly processes; and for processes to be what they are, they depend on spatiotemporal or causal continuity. A process such as a "Mexican wave," is a temporally extended process, with temporal parts consisting in each person standing up slightly after the person next to them does. As Hofweber \& Velleman put the point: "What there is of this process - [one person standing up slightly after the person next to them does] - is not sufficient to determine that particular process is taking place." $(2010$, p. 14) That person could have stood up at that particular moment, just as it actually occurs in sporting arenas, without any 
other persons standing up slightly at other moments so as to give rise to the same process. Therefore, the Mexican wave is not wholly emergent in its temporal entirety within a particular time interval; and, moreover, not even is the Mexican wave fully determined by the event of a person standing up slightly after the person next to them does to be the process that it is. Hence, the relation between the Xs and the $\mathrm{Y}$ in the example of the Mexican wave does not hold ontologically synchronic.

With these conceptual clarifications out of the way, I now turn to expose the arguments that I will pursue here.

\subsection{Argument and scope}

My ultimate aim in this paper is to determine empirically plausible cases of ontological emergence cases, which, in addition to ontological emergence with downward causation, are diachronic, although non-supervenient. In doing so, I shall argue for two points.

First, I shall argue that what Boogerd et al. (2005), Humphreys (2008), McLaughlin \& Bennett (2011) call the standard philosophical account of emergence based on mereological supervenience misses entirely is the dynamics of how higher-level emergent phenomena arise and are maintained over time. Claims involving emergence are ubiquitous in discussions of self-organizing, nonlinear dynamics (Beer 1995; Kelso 1995; van Gelder 1998), artificial life and robotics research (Brooks 1999; Pfeifer et al. 2005), extended and distributed cognition (Clark 1997; Hutchins 1995; Menary 2007; Theiner et al. 2010; Wheeler 2005), enactivism (Di Paolo 2009; Varela et al. 1991), developmental systems theoretic approaches in biology (Griffiths \& Stotz 2000; Oyama et al. 2001), and certain divisions in philosophy of science (Boogerd et al. 2005; Wimsatt 1986). My first argument is thus that what these sciences show us is that there are processes, often involving nonlinear dynamics, giving rise to emergent phenomena, and that these processes, together with the emergent phenomena, escape explanation in the logical and very abstract framework of supervenience. Second, I shall argue that the there is a tension within certain mainstream accounts of extended cognition (EC), and that the search for, and development of, an account of ontologically diachronic emergence, can help highlight this tension. The tension is as follows: some defenders of EC make references to both an ontologically diachronic conception of emergence and employ the relation of supervenience in their writings. In his many writings on issues across dynamical, embodied and extended cognition, Clark $(1997,2001,2008)$ has 
done much to develop the idea that the study of ontologically diachronic emergent phenomena must sit at the very core of the scientific pursuit to understand cognition. However, despite this affinity for ontologically diachronic emergence, Clark also wants to defend claims of the following sort:

\footnotetext{
"A recurrent theme in previous chapters has been the ability of body and world to act as what might now be dubbed "participant machinery" - that is, to form part of the very machinery by means of which mind and cognition are physically realized and hence form part of the local material supervenience base for various mental states and processes.” (Clark 2008, p. 207; italics added)
}

Why would Clark want to apply both ontologically diachronic emergence and supervenience, if these two relations, as I have pointed to already, are mutually exclusive? Perhaps Clark's use of the relation of supervenience is purely dialectical - that is, an attempt to beat the metaphysical internalists by using the latters terminology? Indeed, a charitable reading of Clark's work might suggest this. However, note that if Clark intends to use supervenience for more than just dialectical purposes, that is, to employ the supervenience relation in its strong metaphysical mode, this is impossible, precisely because the notion of ontologically diachronic emergence rules out the justifiability of supervenience. Moreover, insisting on the claim that emergence is compatible with supervenience, if supervenience miss out entirely on the dynamics involved in integrating and maintaining emergent processes or systems, sits uneasily with the larger project of EC, which is to explain the integration of complementary neural and extra-neural elements, together with the transformatory effects of such integration on our cognitive capacities (cf. Menary 2007; Sutton 2010). Consequently, the second argument that I shall pursue here is that friends of EC should avoid using the notion of supervenience unconditionally - both for dialectical purposes as well as for metaphysical ones.

\subsection{Overview}

In section 2, I will consider a couple of examples of emergence in dynamical systems to serve as a backdrop for the discussion that follows in later sections. In section 3, I analyze the relation between emergence and supervenience. In particular, I shall discuss in some detail the philosophical arguments provided by Kim, $(1999,2006)$, whose views on this relationship have been influential in shaping the debate about emergence. During this discussion, I shall use the test cases as a basis for my argument 
that (a) Kim is wrong to insist that supervenience is necessary for emergence, and (b) that Kim is wrong in his rebuttal of emergence, since the issue of downward causation is not as problematic as Kim seems to think. After making a case for ontologically diachronic emergence, I shall turn from looking at lower-order physical cases to considering higher-order examples of socially distributed cognition in section 4. In the final section, I consider the problem facing some of the defenders of mainstream EC due to the endorsement of the supervenience relation.

\section{An example}

An understanding of emergence that has become widespread in the scientific and philosophical models listed above - nonlinear dynamics, artificial life and robotics research, extended/distributed cognition, enactivism, developmental systems theory in biology, and certain strands of philosophy of science - is that emergence is identified with a certain kind of non-aggregative part-whole structure, including selforganization and nonlinear dynamics (Campbell \& Bickhard 2011; Clark 2001; Mitchell 2012; Oyama 2001; Silberstein \& McGeever 1999; Theiner et al. 2010; Wheeler 2005; Wimsatt 1986). That is, a phenomenon will become increasingly less aggregative and consequently more likely emergent as the number, duration, and complexity of the interactions between its parts increases (cf. Wheeler 2005, p.

260; Wimsatt 2000, p. 275) Aggregation we can understand as a simple kind of compositional relationship between a whole and its parts, e.g., the weight of a pile of rocks is the aggregate weight of each component rock making up the whole. However, as Mitchell points out (2012, p. 179), there are several different ways in which compositional aggregation will fail to pick out the appropriate relationship between a whole and its parts.

One way is found in the complexity of dynamical systems represented by self-organizing as well as nonlinear dynamics. Consider the example from dynamical systems theory of a fluid heated from below and cooled from above. Here is how the example goes. Take some oil, put it in a pan, and apply a heat source from below. As the heat is applied it increases the difference in the temperature between the top and the bottom of the oil layer. At a critical threshold, an event called an instability occurs such that the liquid begins to self-organize a coherently rolling motion. This motion is a convection roll. What happens is that the cooler liquid at the top is denser, thereby falling, whereas the liquid at the bottom is warmer (and so lighter), thus tending to rise to the top. Of such a process, Kelso says: 
"The resulting convection rolls are what physicists call a collective or cooperative effect, which arises without any external instructions. The temperature gradient is called a control parameter [but it does not] prescribe or contain the code for the emerging pattern. [...] Such spontaneous pattern formation is exactly what we mean by self-organization: the system organizes itself, but there is no "self," no agent inside the system doing the organizing. [And] the amplitude of the convection rolls plays the role of an order parameter or collective variable: all the parts of the liquid no longer behave independently but are sucked into an ordered coordinated pattern [...]. It is this coherent pattern that is described by the order parameter and it is the order parameter dynamics that characterizes how patterns form and evolve over time." (1995, pp. 7-8; italics in original)

How is the term "emergence" used in this case? The simplest thing to determine is if the phenomenon in question is a property, an entity or thing, a behavior, a mechanism, a process, or some substance? In the case of convection rolls, the type of phenomenon that emerges is a process, in the sense that for it to persist it must evolve over time (cf. Hofweber \& Velleman 2010). But insofar as the process is emergent, in what sense, then, is it novel? Is it novel in terms of some kind of irreducibility, unpredictability or unexpectedness? (Cf. Silberstein 2012) The emergent pattern of convection rolls is not predictable by an aggregation of the behaviors of the individual molecules, but only from the complex (viz., non-aggregative) self-organizing interaction between the component parts and the local order parameter, which is created by the coordination between the parts. So, this particular pattern is not novel because of some form of unexpectedness; rather, it is novel because of its unpredictability. In understanding what "unpredictability" implies in this context, Kim (1999) distinguishes (importantly) between inductive predictability and theoretical predictability. This is an important distinction, because even emergent phenomena such as the pattern of convection rolls are inductively predictable. That is, having observed an emergent phenomenon like cyclical convection rolls emerge whenever any system of components such as molecules are applied heat, we may indeed inductively predict the occurrence of convection rolls. What those defending emergentism are denying is the theoretical predictability of convection rolls given our knowledge of the basis constituents of the phenomenon. Hence, when saying that the emergence of convection rolls is unpredictable, it is theoretical unpredictability that is meant. Furthermore, in what sense can we determine whether what is allegedly explained is a mode of 
ontological, epistemological or perhaps a hybrid explanation crisscrossing both categories? Consider, firstly, what Silberstein \& McGeever say about epistemological emergence:

\footnotetext{
"A property of an object or system is epistemologically emergent if the property is reducible to or determined by the intrinsic properties of the ultimate constituents of the object or system, while at the same time it is very difficult to explain, predict or derive the property on the basis of the ultimate constituents. Epistemologically emergent properties are novel only at the level of description.” (1999, p. 186)
}

The fact that the appearance of convection rolls is novel due to its unpredictability would suggest that it is emergent epistemologically, and hence only novel at the level of description. Obviously, if this is the case, then this example cannot be a case of ontological emergence, in the sense that the definition of epistemological emergence precludes ontological emergence. Recall that ontological emergence is the view that emergent phenomena are not reducible to their ultimate constituents, the molecules in the example being discussed. But, there is a further feature of emergence that is revealed in the case of convection rolls, suggesting that in addition to unpredictability, it is indeed a case of ontological emergence. As Kelso states in the above quotation: "the amplitude of the convection rolls plays the role of [a collective variable]: all the parts of the liquid no longer behave independently but are sucked into an ordered coordinated pattern [...]." (1995, p. 8) That is, the convection cycle involves a kind of “circular causation" (Kelso 1995, p. 9) in which self-organized dynamics of the individual component molecules give rise to a larger pattern, and this higher-level pattern, in turn, has causal efficacy over and above those of the individual molecules, in the sense that the higher-level pattern enslaves those individual molecules into a recurrent pattern of rising and falling (see also Clark 2001, p. 113). So in this dynamical case, certain features are - it would seem - ontologically emergent features of wholes that possess causal capacities not reducible to any of the causal capacities of the individual component molecules. Hence, this example is both emergent epistemologically (due to its unpredictability) and ontologically (due to its higher-level causal efficacy).

Can we be more specific than this? Well we can ask whether the kind of emergence in question is diachronic or synchronic? As I argued in section 1.1, processes depend for their existence on spatiotemporal continuity. To exist in the sense of process is to exist as a dynamical and temporal unfolding in time, and where the process cannot be fully emergent in its temporal entirety within a particular time interval. This suggests that the kind of emergence present in the case of convection rolls is diachronic. 
By “synchronic," recall, I mean an atemporal or instantaneous relation between higher- and lower-level features. That is, had the relationship between higher- and lower-level elements been synchronic, this would have implied that the higher-level process of the convection cycle has to emerge instantaneously - which is not the case. Note, though, that in his survey of emergence, Silberstein (2012) points out that there are two different ways to understand the claim that emergence is diachronic. The first is that " $\mathrm{P}$ has causal powers, capacities, etc., [that is] neither synchronically nor diachronically determined by the base or lower-level causal processes." (2012, p. 630) I do not wish to endorse this meaning of diachronicity, since it implies that the emergent feature(s) is entirely independent from the components parts of the system in which it (or they) are occurring. Note also, that this mode of diachronic emergence is incompatible with the example of convection rolls, in the sense that the recurrent cycle of convection rolls come about due to causal complexity of the parts of the system over time. The second version of diachronic emergence, Silberstein defines accordingly: "[...] P only emerges as, at least in part, a function of some dynamical lower-level or more basic process that unfolds in time. As the system evolves in time new 'higher-level' properties will come into being as a [result] of the unfolding of the more fundamental dynamical process." (2012, p. 630) This is the version of diachronic emergence that fits with the dynamical systems case of convection rolls.

In finishing this section, I want to return to the relationship between diachronicity, on the one hand, and synchronicity, on the other, explored in section 1.1. Following Silberstein \& McGeever (1999), Silberstein (2012), if P is emergent diachronically, then P depends for its persistence upon temporal unfolding at the higher- and lower-level. By "synchronic," then, if $\mathrm{P}$ is emergent synchronically, $\mathrm{P}$ does not depend on temporal unfolding for its existence, viz., the relationship between $\mathrm{P}$ and its base level holds completely at a particular time instant. However, what is the relationship between diachronic and synchronic in the context of emergence? Presumably it is natural to think that there are in the world both synchronic and diachronic relations. But there are at least two possible meanings of the claim that there are in the world both diachronic and synchronic relations. The first is that the two relations are distinct, full stop - either P is emergent synchronically or P is not emergent synchronically. Such an "all-or-nothing" view of emergence is seen in authors who think of the relationship between emergent features and the lower-level constituents as one of synchronic supervenience (see e.g, Broad 1925; Kim 1999, 2006; McLaughlin 1997; van Cleve 1990). The second is that diachronic and synchronic relations are different, because only a diachronic account of 
emergence can explain the dynamics of how emergent features arise and are maintained over time. Unlike the first meaning of this distinction, this formulation is critical of the usefulness of purely synchronic approaches, since what is lost with the synchronic ("snap-shot") view is the dynamics of how processes, often involving self-organizing and nonlinear dynamics give rise to emergent features and regulate their unfolding over time (cf. Humphreys 2008; Mitchell 2012). Thus, another option is to run with this second understanding of the relationship between diachronicity and synchronicity. Note, though, instead of rebutting the applicability of the synchronic dimension simpliciter, one could argue that claiming that a system was in some particular emergent "state," $\mathrm{X}$, at a specific synchronic time instant "really boils down to saying that the average of the system's states during that period of time was X." (Spivey 2007, p. 30; italics in original) Claiming that a system has emergent features synchronically should therefore be understood as a theoretical abstraction, but should not be mistaken as evidence for the claim that that token emergent feature ontologically exists at a synchronic, instantaneous point in time.

This completes my discussion of the example from self-organizing, nonlinear dynamics. I will now consider in some detail arguments from $\operatorname{Kim}(1999,2006)$, whose philosophical arguments have as intended upshots to (a) establish that supervenience and irreducibility are necessary (not sufficient) conditions for emergence, and (b) that emergence is ultimately problematic due to inherent problems with the issue of downward (or circular) causation. As will become clear throughout this section, the view that I hold concerning the diachronic-synchronic distinction, and that I shall argue for, is one that (a) does away with supervenience, and (b) takes synchronic relations to be abstractions from the nature of dynamical and emergent phenomena.

\section{The standard account: Emergence and supervenience}

In his 2006 article on emergence, Kim explicates what he takes emergence to mean. The formulation he suggests is the following: "the intuitive idea of an emergent property stems from the thought that a purely physical system, composed exclusively of bits of matter, when it reaches a certain degree of complexity in its structural organization, can begin to exhibit genuinely novel properties not possessed by its simpler constituents." (2006, p. 548) One might dispute the gloss that a purely physical system is “composed exclusively of bits of matter," because it presupposes the validity of substance ontology (cf. 
Campbell \& Bickhard 2011; Seibt 2009), but otherwise that is the prevalent idea of emergence. That is, ontologically there is just physical "stuff," there is no new substance. In the case from dynamics, there are emergent convection rolls, but this emergent phenomenon is ultimately of the same physical stuff as the lower-level components. Call this idea the principle of physical monism (cf. Stephan 1999). This is Wheeler's (2005) Muggle constraint in operation: if you want to understand how emergent features come about, you had better not appeal to anything non-physical. There is a further principle mentioned in the passage from Kim, call this the principle of organizational features, which states that only those features that none of the components part have in isolation can be emergent.

\subsection{Kim's argument that supervenience is necessary for emergence}

Kim then sets out what he believes to be two necessary conditions that any account of emergence must endorse. These conditions are supervenience and irreducibility. Adding the supervenience claim to the discussion on emergence brings out the third and final principle of standard emergentism, the principle of synchronic determination: According to Boogerd et al., this principle states that "the type of relationship that holds between a system's micro-structure and its systemic [features]: there is synchronic determination if all a system's [features] and dispositions depends on its micro-structure, that is to say, on it's parts' properties and their arrangement." (2005, p. 134) In my discussion of the standard account of emergence, I shall agree with the principle of physical monism and the principle of organizational features, but dispute the principle of synchronic determination.

Concerning supervenience, Kim argues that supervenience must be a necessary condition that any adequate analysis of emergence must satisfy. Consider two wholes that have identical microstructure (i.e., they are composed of identical basic physical constituents configured in an identical structure) yet different concerning the supposedly emergent properties. Applying this to the dynamical case of rising and falling fluid, there may be two molecule-for-molecule identical systems, although only one of them displays convection rolls. If such cases were possible, Kim says, albeit Kim uses a standard example of the relationship between pain and physical neural components, the relation between putatively higherlevel emergent phenomena and their physical base components would be "irregular, haphazard [and/or] coincidental.” (2006, p. 550) In other words, what justification could there be for saying that cyclical convection rolls "emerges from" that specific physical configuration rather than another? Hence, Kim 
rejects the view that an emergent feature of a whole is not determined exclusively by its bits of matter, in a certain structural organization. As Kim says: "If supervenience, or upward necessitation, is taken away, that takes away something essential to the meaning of "emergence" [...]." (2006, p. 550) Therefore, he concludes by stating supervenience is a necessary condition for emergence; that we have to accept the proposition claiming the following:

"Supervenience: If property $\mathrm{M}$ emerges from properties $\mathrm{N}_{1}, \ldots, \mathrm{N}_{\mathrm{n}}$, then $\mathrm{M}$ supervenes on $\mathrm{N}_{1}, \ldots, N_{\mathrm{n}}$. That is to say, systems that are alike in respect of basal conditions, $\mathrm{N}_{1}, \ldots, N_{\mathrm{n}}$ must be alike in respect of their emergent properties." (2006, p. 550; italics in original)

So Kim argues that if $\mathrm{M}$ emerges from $\mathrm{N}_{1}, \ldots, \mathrm{N}_{\mathrm{n}}$, these properties ( $\mathrm{M}$ and its emergent base properties) must meet the supervenience condition. Dovetailing his account of supervenience, with the principle of synchronic determination, Kim advances this additional specification:

"Supervenience/determination: Property M supervenes on, or is determined by, properties $N_{1}, \ldots, N_{n}$ in the sense that whenever anything has $\mathrm{N}_{1}, \ldots, \mathrm{N}_{\mathrm{n}}$, it necessarily has M.” $\left(2006\right.$, p. 550) ${ }^{1}$

\subsubsection{Discussion of Kim’s "supervenience is necessary for emergence claim”}

With this description of Kim's account of the relationship between emergence and supervenience, we are now in a position to critically discuss the question whether emergent features necessarily supervene

\footnotetext{
${ }^{1}$ Note that there are individual and global versions of supervenience, and that these can be decomposed further into stronger and weaker varieties. I mention these varieties here for the sake of completeness, nothing else. For instance, $\operatorname{Kim}(1984,1987)$ defines weak and strong individual supervenience as follows:

"A-properties weakly supervene on B-properties if and only if for any possible world $\mathrm{w}$ and any individuals $\mathrm{x}$ and $\mathrm{y}$ in $\mathrm{w}$, if $\mathrm{x}$ and $\mathrm{y}$ are B-indiscernible in $\mathrm{w}$, then they are A-indiscernible in w."

"A-properties strongly supervene on B-properties if and only if for any possible worlds $\mathrm{w}_{1}$ and $\mathrm{w}_{2}$ and any individuals $\mathrm{x}$ in $\mathrm{w}_{1}$ and $\mathrm{y}$ in $\mathrm{w}_{2}$, if $\mathrm{x}$ in $\mathrm{w}_{1}$ is B-indiscernible from $\mathrm{y}$ in $\mathrm{w}_{2}$, then $\mathrm{x}$ in $\mathrm{w}_{1}$ is A-indiscernible from -indiscernible from $y$ in $w_{2}$."

The difference between these two is that strong supervenience is quantified over possible worlds. The weak version says that if individuals are B-indiscernible, there can be no possible world in which these are A-discernible. The strong formulation stipulates that if B-indiscernible, then it is not possible for two individuals to be Adiscernible, whether in the same or different worlds. The basic idea of "global supervenience" is simply to apply the "indiscernibility considerations" globally to "worlds," rather than to "individuals". Kim (1997) defines the idea of global supervenience accordingly: "Worlds that are indiscernible in respect to subvenient properties are indiscernible in respect to supervenient properties." For weak and strong versions of global supervenience, see Bennett (2004), McLaughlin (1997), Sider (1999), and Stalnaker (1996). Note that in the next section I present an argument developed by O'Connor (2000) that rejects both strong and weak formulation of both individual and global supervenience.
} 
on their physical features? Whether the emergence of convection rolls necessary supervene on its baselevel components and their arrangement? To get us started, I shall present an alternative account of emergence that takes emergence to be ontologically diachronic and non-supervenient, and then apply our test case from dynamical systems to show that emergent phenomena do not necessarily supervene on their lower-level physical components and their configuration. The particular alternative account of emergence I wish to consider here is due to O'Connor (2000) and O'Connor \& Wong (2005), who argue that the standard view of emergence as a supervenience relation is suspect (cf. O'Connor \& Wong 2012, p. 14) ${ }^{2}$. In O'Connor (2000) the target is the relation between a neural mechanism and the emergent properties that this neural mechanism gives rise to. Here I shall substitute the target example of O'Connor with my discussion of convection rolls. With this caveat out of the way, here is the argument provided by O’Connor:

Suppose that when a dynamical mechanism $\mathrm{H}$ comes to have a particular configuration $\mathrm{P}^{*}$ at time $\mathrm{T} 0$, the baseline emergent feature $\mathrm{E}$ is the result at $\mathrm{T} 1$. Because $\mathrm{H}$ is a dynamical system, the specific organization of $\mathrm{H}$ is, at least in part, determined by $\mathrm{P}^{*}$ as it unfolds. Note that $\mathrm{I}$ say that $\mathrm{H}$ is "at least in part" determined by $\mathrm{P}^{*}$ during the period of $H^{\prime}$ 's existence - this is because $\mathrm{H}$ qua being a dynamical system is an open, non-equilibrium system. It is open in the sense that it interacts with its environment - exchanging energy and matter. It is non-equilibrium in the sense that without these interactions, it cannot maintain proper (low) levels of entropy (cf. Kelso 1995, p. 4). Hence we cannot presuppose that $\mathrm{H}$ is fully determined by $\mathrm{P}^{*}$ at any point in time, e.g., at T1. $\mathrm{P} 0$ is the remaining aspect of $H$ 's internal states at T0, and P@ is the summation of factors in H's immediate environment that have an influence on the state of $\mathrm{H}$ at $\mathrm{T} 1$. Let " $\rightarrow$ " represent the causal relation between component properties. According to O'Connor, this gives us the following relationships (2000, p. 111):

- $\quad \mathrm{P}^{*}$ at $\mathrm{T} 0 \rightarrow \mathrm{E}$ at $\mathrm{T} 1$

And

- $\quad \mathrm{P}^{*}+\mathrm{P} 0+\mathrm{P} @$ at $\mathrm{T} 0 \rightarrow \mathrm{P}^{*}+\mathrm{P} 1$ at $\mathrm{T} 1$

This last conjunction highlights the total internal state of $\mathrm{H}$ at $\mathrm{T} 1$, where $\mathrm{P} 1$ is the remainder beyond $\mathrm{P}^{*}$. In the language of dynamical systems theory, we can understand the total internal state of $\mathrm{H}$ to be

\footnotetext{
${ }^{2}$ See Humphreys' (1997) "fusion" account of emergence for a different kind of critique of the standard account of emergence, although one the equally builds on the idea that emergence is diachronic and dynamic.
} 
sets of interdependent variables, where a variable is a simple entity that can have a different state or value at different times (cf. van Gelder 1998, p. 616). According to O'Connor, E at T1 will be a joint determiner of $H^{\prime}$ 's physical configuration at T2, but not $H^{\prime}$ 's continuing to have $\mathrm{P}^{*}$. Moreover, E may also help in determining, at T2, the emergence of another feature, E2. On O'Connor's account, this looks diagrammatically as follows (Fig. 1):

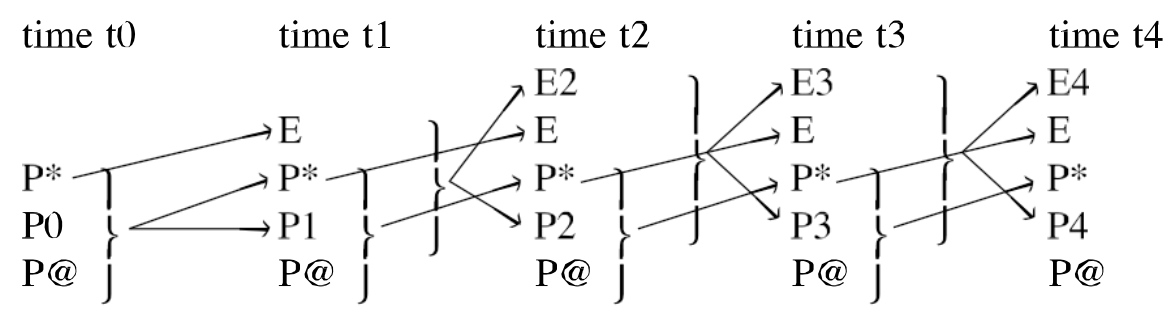

Fig. 1: Diagram of the evolution of emergent features (adapted from O’Connor 2000, p. 111)

Kim's invocation of supervenience to deliver a non-coincidental conception of emergence raises the question whether there can exist two systems that are alike in respect of lower-level features, yet that are not alike in respect to their emergent features. Indeed, if such a possibility turns out to exist, which O'Connor's formal argument claims that it does, this entails the failure of supervenience relations in accounts of ontologically diachronic emergence.

In our test case, $\mathrm{H}$ is a dynamical system comprised of $\mathrm{P} *, \mathrm{P} @$ (in this case, $\mathrm{P} @$ is the source of heat applied), and P0 at time T0. Because of the inherent nonlinearity of $\mathrm{H}$ a liquid heated only weakly from below will not display any macro-motion. By "nonlinearity" I mean that if there is an interaction between two components, $\mathrm{X}$ and $\mathrm{Y}$, say, the value of $\mathrm{X}$ does not increase proportionally to the value of Y, but main remain at zero, e.g., until Y reaches a certain critical threshold (see e.g., Clark 2001, p. 115). However, at a critical value of the temperature gradient the liquid will start to show the familiar macroscopic rolling motion we know as convection rolls. In the language of dynamical systems, here the liquid is in a bi-stable dynamical state such that the convection rolls can rotate in one direction or in the other direction. That is, either from right to left, or from left to right in its rolling motion. Note that which direction of the rolling motion that emerges is random (see figure 1.1. in Kelso 1995, p. 6). This 
possible state and that is a state of rest - diagrammatically shown by the liquid being in a stable (deep) energy well. At the instability point, a bifurcation (or branching) occurs such that $\mathrm{H}$ moves away from its stable state to a bi-stable state - diagrammatically shown by the potential of the liquid to be in one of two dynamical states. That is, "two rolling motions whose rotation speed is equal but opposite emerge spontaneously, [with only] one, of course, realized in the experiment." (Kelso 1995, p. 10) What was previously a stable state is now an unstable state.

Now, consider, first, the status of the baseline emergent feature E, with respect to the times $\mathrm{T} 0$ and $\mathrm{T} 1$ in O'Connor's diagram. Here $\mathrm{E}$ is absent at T0 but present at T1. From this specification, O'Connor points out the following: "The underlying physical [features] are different, too, but that is not the reason for the difference in emergent [features]. For the differentiating factors (P0, P1 and [...] P@) are, by hypothesis, not directly relevant to the occurrence of E. P* alone is so relevant.” (2000, p. 112) This might sound a bit strange to omit P0, P1, and P@ from consideration in this discussion. Why does O'Connor do this? On the one hand, Kim clearly states the idea of emergence is the thought that a physical system, composed of only bits of matter and their organization, can begin to exhibit emergent features. This is what $\mathrm{P}^{*}$ implies. On the other hand, P0 and PI represent any remaining physical elements that do not participate in the generation of emergent phenomena, where P@ is a parameter outside of H. For readers familiar with dynamical systems, the omission of certain parameters, because they are not relevant to the occurrence of the phenomenon in question, should not be troublesome (see e.g., Beer 1995, p. 181). With this clarification out of the way, note that $\mathrm{E}$ is absent in T0, but present immediately thereafter in T1. Consequently, in the first instantiation of $\mathrm{H}$, no emergent features will be present. Even if $\mathrm{H}$ at $\mathrm{T} 0$ has reached to point of instability, this process has to unfold over a period of time; hence, even if $\mathrm{H}$ begins the branching movement at $\mathrm{T} 0$, yet sharing with $\mathrm{H}$ at $\mathrm{T} 1$ what is specified in $\mathrm{P}^{*}$, only one of the physical configurations has $\mathrm{E}$ (O’Connor 2012, p. 112). In other words, let us say we have two dynamical systems both of which have alike physical configuration, represented by $\mathrm{P}^{*}$. In one system the interaction of the molecules is faster, because of the higher temperature gradient, where this is not the case in the second system; in one system there is rolling motion and in the other system there is not rolling motion; but the arrangement of material bits might be the same across these two systems. Importantly, rolling motions are not the only possibilities. In an open container, for instance,

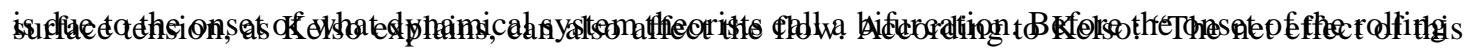

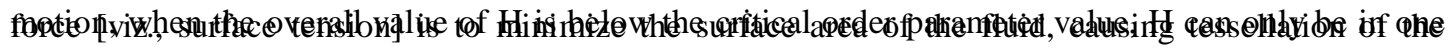


surface and the formation of hexagon cells. In the center of each hexagon, liquid rises, spreads out over the surface, and sinks at the perimeter where the hexagons join.” (1995, pp. 7-8) Plausibly, a couple of dynamical systems might exist that are alike with respect to $\mathrm{P}^{*}$ at $\mathrm{T} 0$, but where one has $\mathrm{E}$ (the cyclic pattern of convection rolls) at $\mathrm{T} 1$, whereas the other has $\mathrm{E}^{*}$ (the pattern of liquid rising, spreading out over the surface, and sinks at the perimeter) at T1. This is plausible, and can be explained by taking into account the mechanisms involved in the generations of these two different emergent patterns. As Kelso explains: "An important point is that two quite distinct mechanisms - one to do with buoyancy and the other surface tension - can give rise to [either] the same pattern [or to two different patterns]." (1995, p. 8) Crucially, neither buoyancy nor surface tension are elements of $\mathrm{P}^{*}$, since $\mathrm{P}^{*}$, even on the account provided by Kim, is a physical system composed only of bits of matter and their organization; however, buoyancy and surface tension is neither bits of matter nor the organization of bits of matter both mechanisms are the result of a system organized in a particular manner. Now, if this is true, then O'Connor is correct to insist that emergence as a supervenience relation is problematic. Note that once we consider the contribution of a system's prior trajectory through its dynamical state space, we get the picture that prior systemic elements play a role in determining emergent features of a system, and that emergent features themselves are temporally extended in time. Unfortunately for those insisting on the compatibility of emergence and supervenience, the relation of supervenience fails to apply to cases in which the relata of emergence are ontologically diachronic.

Consider, secondly, that the supervenience/determination condition states that if some feature E supervenes on, or is determined by, features $N_{1}, \ldots, N_{n}$, it necessarily has E. However, what the example of convection rolls shows us is that there can be a divergence between the emergent features of two dynamical systems in the face of physical similarity at the base level. As O'Connor puts it: "You might have the underlying physical properties $\mathrm{P}^{*}$ and $\mathrm{P} 2$ without having had E2. For E2 is a product of the immediately prior state of $\mathrm{H}$ (comprised of $\mathrm{P}^{*}, \mathrm{P} 1$, and $\mathrm{E}$ ). This prior state presumably could have been different (such that E2 would not occur at t2) [...].” (2000, p. 112) Because dynamical systems are open and undergo bifurcations over time, open systems such as the one illustrated in this discussion often have several options given the same underlying physical features and environmental conditions. 
provide additional reasons for my skepticism against emergence as a supervenience relation, I consider a different example from which I shall draw out two problems with the assumption that emergence is a supervenience relation.

Consider what evidence on the molecular structure of water indicates about the part-whole relation between the macroscopic pattern of water and its components parts, here molecules of water. If the macroscopic pattern of water emerges from its lower-level physical constituents, and if one further assumes that this relation of emergence in this case is supervenient, this entails that the macro-scopic pattern of water has its features synchronically. However, water, Ladyman \& Ross inform us "is composed of oxygen and hydrogen in various polymeric forms, such as $\left.\left(\mathrm{H}_{2} \mathrm{O}\right)_{2},\left(\mathrm{H}_{2} \mathrm{O}\right)_{3}\right)$, and so on, that are constantly forming, dissipating, and reforming over short time periods in such a way as to give rise to the familiar properties of the macroscopic kind water." (2007, p. 21; italics added) That is, water is an emergent feature of a complex dynamical system, and it "makes no sense to imagine it having its familiar properties synchronically.” (Ross \& Ladyman 2010, p. 160; italics added) Insofar as water has emergent features, the presupposition of the standard and representative view of emergence - that this is a supervenience relation - fails to capture the dynamics of how the higher level is emergent and how it is maintained as it unfolds over time. Furthermore, considering the different phases of water, and related thermodynamic considerations of how the macroscopic whole "water" relates to its parts, van Brakel begins by asking whether water consists of $\mathrm{H}_{2} \mathrm{O}$ ? At a first approximation, water is not composed of $\mathrm{H}_{2} \mathrm{O}$, since the part-whole composition of water is context sensitive and contingent. Note that by "context sensitive and contingent," I shall follow Oyama et al. (2001) and take this to mean that the "significance of any cause is contingent upon the state of the rest of the system." (2001, p. 2). For instance, in liquid water, water molecules form larger clusters via interaction. Or, in ice, as van Brakel points out, "there aren't really individual molecules. [In fact, in] solid neon one might [even] come across hexamers." (2010, p. 131) But if the different phases of water reflect differences in their microstructure, one might think that surely it is possible to identify the relevant molecules as being like this? However, according to van Brakel, water "contains isotopic variants such as $\mathrm{HDO}$ and $\mathrm{D}_{2} \mathrm{O}$. The physico-chemical properties of deuterium oxide are different from those of ordinary water, and therefore, its role in biochemical processes." (2010, pp. 131-32) Hence, the answer is that we cannot

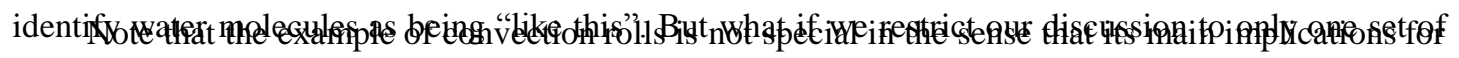


isotopes, then surely all $\mathrm{H}$-atoms (hydrogen atoms) in water are identical? Again van Brakel answers this question with a straightforward "no," since there "is [both] ortho- and para-hydrogen, which have different physico-chemical properties." (2010, p. 132) All right the reader might wonder; nevertheless, even if the part-whole relation between water and its constituents is context sensitive, is it not still the case that a water molecules always behaves as a $\mathrm{H}_{2} \mathrm{O}$ molecule? Fascinatingly, according to van Brakel the answer to this is: "No! [...] in some circumstances, water molecules are not "seen" as $\mathrm{H}_{2} \mathrm{O}$ by entities which with it interacts, but more like something like $\mathrm{H}_{1},{ }_{5} \mathrm{O}$." $\left(2010\right.$, p. 132) ${ }^{4}$ We cannot even assume that water always consists of interactions between $\mathrm{H}$ and $\mathrm{O}$ atoms. Indeed, "there is some probability (however, small) that a water molecule will suddenly transform into a Neon atom.” (Belyaev et al. 2001; quoted in van Brakel 2010, p. 132) Hence, one problem with the standard account of emergence as a supervenience relation is that because of its commitment to supervenience, and since this metaphysical relations is supposed to hold synchronically, it misses out on the dynamics by which oxygen and hydrogen, in various polymeric forms such as $\left.\left(\mathrm{H}_{2} \mathrm{O}\right)_{2}\right),\left(\mathrm{H}_{2} \mathrm{O}\right)_{3}$, and so on, are constantly forming, dissipating, and reforming over very short time periods, thereby giving rise to the so familiar features of the macroscopic kind water (cf. Ross \& Ladyman 2010, p. 21).

This points us in the direction of a related problem, which comes about through recognizing that as a part-whole relation, the standard account of emergence as a supervenience relation presupposes that relational (i.e., extrinsic) properties supervene on non-relational (i.e., intrinsic) properties of its lower-level, subvenient base (cf. Lewis 1983; McLaughlin \& Bennett 2011). "Intrinsic properties" are normally understood to be those properties that an object may possess independently of everything else that exists, or independently of whether or not anything else exists. For example, the charge and mass of a classical particle are thought to be intrinsic properties of an object, whereas "being south of New York" is dependent on someone's relation to something else. In the case of water, supervenience as normally understood fails to obtain. It fails because of the context sensitivity and contingency of the part-whole relations characteristic of water. If emergent wholes come about through continuous and reciprocal interaction between components at the emergent base level, and if the features of the parts cannot be determined independently of the context in which they are embedded, then this challenges the idea that relational features supervene on non-relational features. Especially, it challenges the very

\footnotetext{
4 "Schewe et al. (2003): A water molecule's chemical formula is really not $\mathrm{H}_{2} \mathrm{O}$, at least not from the perspective of neutrons and electrons interacting with the molecule for only attoseconds (less than $10^{-15} \mathrm{~s}$ )." (Cited in van Brakel 2010, p. 132; footnote 42)
} 
foundation presupposed by supervenience relations, namely that extrinsic stuff supervenes on intrinsic stuff (cf. Humphreys 1997; Ladyman \& Ross 2007; O’Connor 2000).

These various considerations suggest that emergent features do not necessarily supervene on their physical base level ${ }^{5}$.

\subsection{Kim's argument against downward causation}

If it turns out to be correct that at least in cases of dynamical systems, emergence does not by necessity presuppose supervenience, Kim has a second argument that threatens to render the notion of emergence incoherent. As Kim rightly notes, concerning ontological emergence, it "is critically important to the emergentist that emergent properties have distinctive causal powers of their own, irreducible to the causal powers of their base properties." (2006, p. 557; italics added) Otherwise, it would seem, that putative emergent phenomena would be mere epiphenomena. Any account of ontological emergence, including mine, is thus committed to the possibility of downward (or circular) causation (cf. Campbell \& Bickhard 2011, p. 42). Across numerous publications, Kim has repeatedly used the following argument to establish that all forms of non-reductive physicalism (e.g., emergence), which separates between higher-level features and their compositional lower-level components and activities collapses to some form of reductive physicalism. If this argument is successful, it leaves no room for ontological accounts of emergence.

Here is my iteration of Kim's argument: Suppose there is an emergent feature, M, with causal powers, and that some instantiation of it brings about another emergent feature $\mathrm{M}^{*}$. But, ex hypothesi,

\footnotetext{
${ }^{5}$ Note that thus far my discussion of supervenience has taken the relation between A-features and B-features to be one of indiscernibility such that " $\mathrm{x}$ and $\mathrm{y}$ are A-indiscernible if and only of they are exactly alike with respect to Aproperties; similarly for B-indiscernibility." (McLaughlin \& Bennett 2011, p. 14) However, in addition to varieties of individual and global indiscernibility-based supervenience, there are also versions of similarity-based accounts of supervenience, where things "that are very much alike in B-respects must also be very much alike in A-respects. As with indiscernibility-based supervenience, similarity-based supervenience comes in both weak and strong versions:
}

"A weakly supervenes $s_{\text {sim }}$ on B if and only if for any world $w$, and for any $\mathrm{x}$ and $\mathrm{y}$ in $\mathrm{w}$, if $\mathrm{x}$ and $\mathrm{y}$ are not largely different with respect to B-properties, then they are not largely different with respect to Aproperties." (McLaughlin \& Bennett 2011, p. 27; italics in original)

"A strongly supervenes $s_{\text {sim }}$ on $\mathrm{B}$ if and only if for any worlds $\mathrm{w}_{1}$ and $\mathrm{w}_{2}$, and for any $\mathrm{x}$ in $\mathrm{w}_{1}$ and $\mathrm{y}$ in $\mathrm{w}_{2}$, if $\mathrm{x}$ in $\mathrm{w}_{1}$ is not largely different from $\mathrm{y}$ in $\mathrm{w}_{2}$ with respect to B-properties, then $\mathrm{x}$ in $\mathrm{w}_{1}$ is not largely different from $\mathrm{y}$ in $\mathrm{w}_{2}$ with respect to A-properties." (McLaughlin \& Bennett 2011, p. 27; italics in original)

I mention this issue here so as not to beg the question against similarity-based supervenience. Nevertheless, the point to note is that it remains an open question whether there are (or has been) any interesting philosophical uses of the idea of similarity-based supervenience (cf. McLaughlin \& Bennett 2011, p. 27). Hence, as such it poses no immediate threat to my argument for ontological emergence that is diachronic/dynamic but non-supervenient. 
$\mathrm{M}^{*}$, as an emergent feature, must be composed by its physical base $\mathrm{P}^{*}$, without which $\mathrm{M}^{*}$ would not be present. The initial point that Kim wants to make is that for this story to be coherent, we must accept that the instance of $\mathrm{M}$ caused $\mathrm{M}^{*}$ to be instantiated by causing the instantiation of $\mathrm{P}^{*}$. But note, as an emergent, M must itself have a physical base, call this base P. Furthermore, if M supervenes on $\mathrm{P}$, then the instantiation of $\mathrm{P}$ should be sufficient for the instantiation of $\mathrm{M}$. At this juncture in the argument, Kim invokes the principle of transitivity to assert the following: if $\mathrm{M}$ is causally sufficient for $\mathrm{P}^{*}$, and thereby $\mathrm{M}^{*}$, then $\mathrm{P}$ is causally sufficient for both $\mathrm{P}^{*}$ and $\mathrm{M}^{*}$. Hence, as Kim points out: "This appears to make the emergent property $\mathrm{M}$ otiose and dispensable as a cause of $\mathrm{P}^{*}$; it seems that we can explain the occurrence of $\mathrm{P}^{*}$ simply in terms of $\mathrm{P}$, without invoking $\mathrm{M}$ at all. [...]. If $\mathrm{M}$ is somehow retained as a cause, we are faced with the highly implausible consequence that every case of downward causation involves causal overdetermination (since P remains a cause of $\mathrm{P}^{*}$ as well).” (2005, p. 558)

In his (2006), Kim concludes his argument against emergence by say that if this argument cannot be successfully rebutted, it threatens to bankrupt the central idea of ontological emergence, namely that emergent features can have causal efficacy over and above those of the components making up the base level. As he says: "If downward causation goes, so goes emergentism." (2006, p. 558)

\subsubsection{Discussion of Kim's argument against downward causation}

The self-organization and nonlinearity that is characteristic of the dynamical complexity (e.g., bifurcations) in dynamical systems, like the case of convection rolls and water, reveals that while deterministic, the emergent behaviors are unpredictable given their sensitivity to variations in starting and evolving boundary conditions (cf. Mitchell 2012, p. 181). But this gives us only epistemological emergence, whereas Kim's argument against emergence is leveled at ontological emergence with downward causation. To problematize Kim's critical argument, I need to show that the idea of downward causation is not as problematic as Kim thinks. Indeed, as Campbell \& Bickhard (2011) point out, there is no shortage of examples of downward causation. Consider, e.g., Couzin \& Krause's (2003) identification of emergence in flocking starlings:

"[I]t is usually not possible to predict how the interactions among a large number of components within a system result in population-level properties. Such systems often exhibit a recursive, nonlinear relationship between the individual behavior and collective ('higher-order') properties generated by these interactions; 
the individual interactions create a larger-scale structure, which influences the behavior of individuals, which changes the higher-order structure, and so on.” (2003, p. 3; italics added)

Harking back to the language of dynamical systems, an order parameter (or collective variable) comes about through the coordination between individuals (birds, molecules, and so on), which, in turn, have an influence on the parts. What the contemporary scientific sense of emergence gives us are concrete accounts of how and why multiple top-down and bottom-up, forward and reverse feedback, loops (a) can result in the theoretical unpredictability of emergent phenomena, and (b) the existence of wholly natural modes of downward causation. Or, as the dynamical systems theorists call it, circular causation (cf. Kelso 1995). As Clark says about the continuous self-organizing, top-down and bottom-up loops in dynamical systems: "This cycle involves as kind of "circular causation" in which the activity of the simple components leads to a larger pattern, which then enslaves those same components, locking them into a cycle [in the case of convection rolls] of rising and falling." (2001, p. 112) Now, while I am sure some will find the validity of Kim's logic persuasive, there are assumptions made that are clearly open to criticism. First, Campbell \& Bickhard argue that Kim's argument begs the question. That is, it says that $\mathrm{P}$ is nomologically sufficient for $\mathrm{M}$. However, since this is precisely the claim of physicalism, it cannot be used as a premise in an argument against the possibility of ontological emergence. Even if this does beg the question, there is a related problem, namely: even if the conditions arising at a higher level are constituted by a particular configuration of components and their activities, and if the latter is nomologically sufficient for the emergence of the former, this does not rule out the possibility that once generated, the higher-order features may "act back" upon, and thus shape, the features of the base-level constituents (cf. Craver \& Bechtel 2007, p. 558). Second, Kim's argument against downward causation is built on the justifiability of supervenience; that a set of A-properties supervenes on another set of Bproperties if and only if no two things can differ in respect to A-properties without differing in respect to their B-properties. But as I have shown, this premise is problematic. As O'Connor stresses: "there might be two objects having identical $[\ldots]$ physical properties $[\ldots]$ and existing in the same external circumstances, yet one [is emergent] and the other [is not]." (2000, p. 112)

\section{In search for ontological emergence in socially distributed cognition}


Thus far I have argued against the standard view of supervenience in favor of emergence as ontological and diachronic. I have based these arguments on relatively simple physical systems such as convection rolls and water. These cases I have chosen deliberately to show that we do not have to scale all the way up to cognitive or social systems to expose several key flaws in the standard view of emergence as a supervenience relation; instead it is entirely possible to stay at the level of simple physical systems, where these debates in the literature are often fought. I now want to change the pace a bit, in the sense that I wish to move from examples such as convection rolls and water to higher-level cases of socially distributed cognition in order to show that the concept of ontologically diachronic emergence can be successfully applied across a multiplicity of different levels.

\subsection{Stigmergic path formation}

Many group-living animals, including humans, often create path systems the result of which is highly advantageous for each of the individuals without this necessarily being the intent of any of the individuals taking part in the creation of spatiotemporal patterns such as a path. Furthermore, even if individuals interacting directly with one another do not generate the process of path formation, it is still the case that the "pattern-forming mechanism" (cf. Couzin \& Krause 2003, p. 9) persists at the collective level, in the sense that it operates through indirect interaction by environmental modification - hence the term "stigmergic path formation". Herds of wildebeest create efficient foraging trails; just like ants, whereas humans are proficient at creating interconnected path-networks in urban areas. Focusing on the emergence of human trails, Helbing et al. (1997a, 1997b) modeled processes of trail formation by mobile individuals in the "Active Walker" computational model. This model enables experimenters to manipulate the perception (and thus the choices) of (virtual) individuals by varying two important parameters for path formation; the first, path visibility (i.e., the extent to which an individual is influenced by distant patches' travel ease); and the second, the decay rate of a path (i.e., how quickly the influence of a step on a patch's ease of travel dissipates). In the experiment performed by Helbing et al., the walkers (individuals) were assumed to have the ability to modify the environment through or in which they move (see Fig 2.). 
A

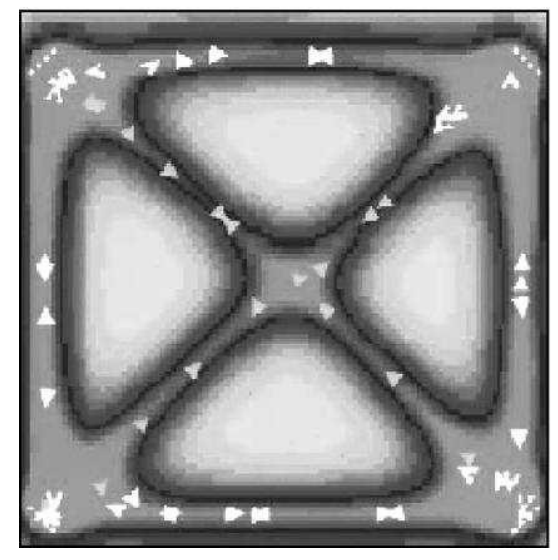

B

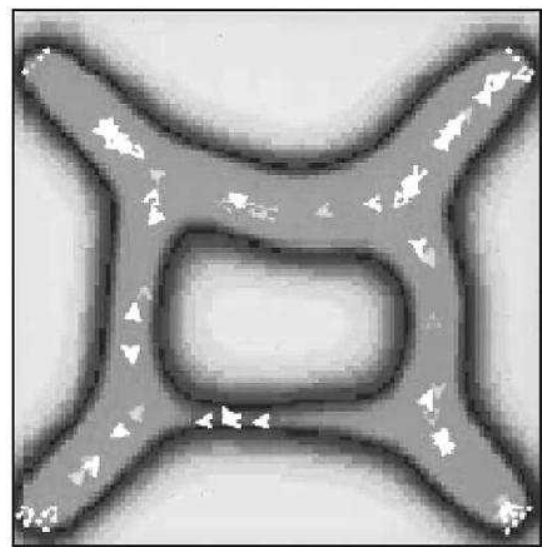

Fig. 2: Computer simulation of human trail systems. (A) Initially walkers will take more-or-less direct routes between the four entry/exit points in the corners. The instantaneous velocities of walkers are shown as arrowheads. (B). After a period of time a shared trail system forms. (From Helbing et al. 1997b; depicted in Couzin \& Krause 2003, p. 10)

In their model, these modifications are represented as arrowheads and the difference in trail systems in (2.A) on the one hand and (2.B) on the other. Furthermore, within the model developed by Helbing et al., it is assumed "that people will tend to take the shortest route to their destination but tend to reconcile this global goal-oriented behavior with a relatively local preference to walk on previously (less bumpy) ground." (Couzin \& Krause 2003, p. 10) As we can see in figure 2.A., walkers initially select the most direct route to their respective destination. However, over time (figure 2.B), the trails used most often become more confortable (e.g., less bumpy) and consequently more attractive. This, in turn, influences the local characteristics of the trail system. As Couzin \& Krause mention: "sections of trails become shared by walkers with different desired routes, creating a trail system in which the overall length is reduced. Increasing comfort means that a given section of trail is more likely to be used in [the] future, which further increases its comfort, and so on (autocatalysis)." (2003, pp. 10-11) That stigmergic path formation generate emergent phenomena is not surprising; indeed, what emerges through nonlinear, self-organizing interactivity at the level of individual pedestrians is a path system, emergent from the behaviors of people. Note as well that the kind of emergence in 2.A and 2.B is diachronic rather than synchronic, since both of these evolve over time and are constantly forming and reforming due to local perturbations from both individuals and environmental conditions. At this stage in the overall argument for a conception of ontologically diachronic emergence, I want to adopt the 
framework developed throughout this paper so as to conceive the reader that this example in a case of emergence that is ontologically diachronic.

First, there is nothing in the case of stigmergic path formation that prevents one from using either one of two possible epistemological species of the synchronic-diachronic distinction. I have not said anything about this distinction yet, so I will have to briefly introduce it. If one claims that P exists at an epistemologically synchronic point in this, this claim expresses a description of a system being at time T1, as opposed to T2, say, relative to some scientific model. Contrariwise, if one claims that P exists in an epistemologically diachronic manner, this amounts to the that P's existence is best understand as unfolding over time. Consequently, one can justifiable describe $\mathrm{P}$ as existing either a at particular instant or as existing across a set of time interval. But, care is required when making these claims, because in dynamical systems - like the system from which emergent pattern of trails emerge - time in considered to be continuous, in the sense that time is not decomposable into discrete quanta (cf. Spivey 2007). If time is continuous, then changes in a systems systemic state must equally be continuous. Image that $\mathrm{P}$ is an emergent trail system, the claim that P exists entirely at a synchronic moment boils down to the claim that "the average of the system's states during that period of time was [P]." (Spivey 2007, p. 30) That is to say, in a dynamical system, where time cannot be reduced to a set of discrete units, the claim $\mathrm{P}$ can be explained in epistemically synchronic terms must not be mistaken for the claim that $\mathrm{P}$ itself is ontologically synchronic. One source of intuition, I suspect, for somebody to insist that the ontological view of synchronicity captures a coherent form of emergence is if one thinks of the existence of $\mathrm{P}$ as a form of travel through time. On this conception of emergence, $\mathrm{P}$ is emergent at every moment time at which P exists through P's occupation of different moments in time in its temporal entirety. On the account provided by Hofweber \& Velleman, this way of thinking “is analogous to an object's travelling through space and occupying different parts of space in its spatial entirety.” (2010, p. 3) Here I want to follow Hofweber \& Velleman, who state that:

"But the latter is only coherent because the object occupies different parts of space at different times. What makes it possible for an object to occupy different places in its spatial entirety is that there is another dimension, time, along which the object changes its position in space. But movement in time cannot be understood in this way, since the dimension along which the object changes position would be the same as the one in which its position is being changed." (2010, p. 3; italics in original) 
The problem with considering the relation of emergence between $\mathrm{P}$ and P's constituents, the Xs, as one that turns on ontological synchronicity is, if we follow Hofweber \& Velleman, a tendency to represent the relation of emergence spatially, e.g., by drawing it on a blackboard or representing it in a diagram. This way of thinking, however, is misleading, since the spatial representation of a dynamical system and a dynamical systems time continuous character are not analogous. In the case of stigmergic path formation, the processes from which an emergent trail emerges are temporally extended processes, i.e., that the processes giving rise to $\mathrm{P}$ do not exist entirely within one particular spatiotemporal moment. In this sense, stigmergic path formation is diachronically emergent, in that it is a result of certain dynamic processes that unfolds in time, which will continue to give rise to new higher-level features through temporal unfolding.

\subsection{Cumulative downstream epistemic engineering}

Another example of socially distributed cognition involves process of organism-driven environmental modification, which, after, Odling-Smee (1988) has become known as niche construction. Niche construction, as defined by Laland et al., refers to:

"[T]he activities, choices and metabolic processes of organisms, through which they define, choose, modify and partly create their own niches. For instance, to varying degrees, organisms choose their own habitats, mates, and resources and construct important components of their local environment such as nests, holes, burrows, paths, dams, and chemical environments." (2000, p. 131)

All living animals, through their metabolism, their choices and activities, at least in part construct and demolish each other's ecological habitats across both local and global scales. A classical example is the beaver's dam. Through iterative niche construction, beaver's may transform their environment, thereby modifying some of the selection pressures that affect the fitness of genes expressed in several different traits. Because of this, niche construction is, after natural selection, the second major component and participant in evolution (Laland 2004, p. 316). For instance, the niche construction of dam building that beavers engage in may modify the selection pressures affecting the fitness of such diverse genes expressed in such different traits as teeth, tail, feeding behavior, diseases, susceptibility to predation, and so on (Laland 2004, p. 317). Another excellent example is the burrowing activities of earthworms. 
That is, through their burrowing activity, their dragging organic material into the soil, together with the process of mixing it up with inorganic material and their casting, earthworms alter the structure as well as chemistry of the soils in which they live (Laland 2004, p. 319). According to Laland: "As a result of their industry, earthworms affect ecosystems by contributing to soil genesis, to the stability of soil aggregates, and to soil porosity, aeration and drainage. Because of the casts contain more organic carbon, nitrogen and polysaccharides than the parent soil, earthworms can affect plant growth by ensuring the rapid recycling of many plant nutrients [and] probably benefit from the extra plant growth they induce by gaining an enhanced supply of plant litter." (2004, pp. 319-320) But what exactly is the benefit of all their activity for the local earthworm? The burrowing activity is important because earthworms, prior to their presence on land, were originally aquatic organisms. Laland sums up the importance of this as the says that only by "co-opting the soils that they inhabit and the tunnels they build to serve as accessory kidneys that compensate for their poor structural adaptation [...]," (2004, p. 321) can earthworms tackle the physiological demands of a different water-and salt-balance on land. For my present purposes, these two examples illustrate the powerful point that once emergent the product of flourishing niche construction - e.g., the beaver's dam - can be viewed as replicators for additional traits, the effects of which are transgenerationally mediated. In other words, the activity of niche construction leads to the creation of feedback cycles running across disparate time-scales. In the two cases thus far mentioned, circular causation runs over phylogenetic and ontogenetic time.

These two examples illustrate what we might call pragmatic engineering. However, another very powerful force of niche construction is what Sterelny (2003) refers to as cumulative down-stream epistemic engineering. By "cumulative downstream epistemic engineering," Sterelny intends to highlight the transformatory effect on human cognition through cultural transmission of knowledge as well as practices generated over individual lifetime and passed downstream to the next generation. One quite simple, although highly illustrative, case of epistemic engineering is mentioned by Clark (2001, 2008), namely how expert bartenders pass down to novice bartenders an epistemically engineered or constructed niche consisting of distinctively shaped glasses and cultural practices. Within this already structured niche, the problem of remembering which sequence of drinks to prepare for the novice is transformed. On the one hand, the problem is transformed into the problem of selecting and arranging distinctively shaped glasses at the time of ordering. On the other hand, this active structuring of the bar area has the effect of "creating persisting spatially arrayed stand-ins for drink orders, actively structures 
the local environment to press more utility from basic modes of visually cued action and recall." (Clark 2008, p. 62; see also Clark (2001, p. 141)) The recurrent pattern of actively engineering the workspace by arranging a sequence of differently shaped glasses, together with the practices going along with this, transforms the accuracy by which a bartender remembers a multiple drink order in a noisy environment - like bars tend to be.

What emerges here is a cultural practice enabling the novice as well as expert to epistemically engineer their local surroundings. Cultural practices, according to Hutchins, are "emergent products of dynamic distributed networks of constraints. Some constraints may be internal and mental [...], some constraints arise from the mechanics and physiology of the body, some constraints may be provided by engagement with material artifacts and some from interactions with social others." (2011, p. 441) For instance, as Clark says about epistemic engineering: "This explanatory strategy thus depicts much of what is most distinction in human cognition as rooted in the reliable effects, on developmentally plastic brains, of immersion in a well-engineered, cumulatively constructed cognitive niche.” (2008, p. 68) In the case of diachronic emergence, the effects of such cultural practices exhibit downward causation. A simple example of this is Roepstorff et al's use of Näätänen et al's. (1997) study of the phenomenon of phoneme perception. This work suggests top-down effects of cultural practices upon the functional patterning of the brain. As Roepstorff et al. say about the relation between cultural practices and the brain:

"Patterned practices at the level of social interaction correlate in relevant ways with neural and psychophysical patterns, and in the same way that social practice forms patterns, large-scale brain signals as well as other psychophysical signals generated during particular task performances can be analyzed to expose significant patterning.” (2010, p. 1052)

Näätänen et al's. (1997) findings on the language-specific phoneme representations confirm Roepstorff et al's hypothesis. Based on a mismatch-negativity (MMN) paradigm, Näätänen et al presented Finnish and Estonian participants with the task of discriminating between very similar vowel structures. In this study, where subjects exposed to unattended sounds in certain rhythmic patterns, Näätänen et al. (1997) established that the primary auditory cortex in the left hemisphere is highly sensitive to changes in predictable sound patterns (1997, p. 432). In the first set of the experiments Näätänen et al. utilized Finnish and Estonian language speakers because of a relatively small discrepancy between the two 
“Clark \& Chalmers' (1998) aim was to show that external traces (pencil marks in a notebook) may /õ/, not found in Finnish. In the experiment, the speakers were also presented as deviants a prototype of this sound, along with vowels existing in both languages (/o/ and /ö/), and a non-prototypical vowel (located between /e/ and /ö/) (Näätänen et al. 1997, p. 432). The result of this experiment was that the Finnish speakers showed significantly higher mismatch negativity when exposed to prototypical vowels in their native language than when exposed to the Estonian vowel /õ/. According to Roepstorff et al. (2010): "This demonstrated that when an acoustic deviant is presented, a vowel prototype in the native language elicits a larger MMN than could be explained by the acoustic properties alone." (2010, p. 1053) This evidence lends support to the claim that "brains may become patterned by participating in practices structured in particular ways." (Roepstorff et al. 2010, p. 1053; see also Vogeley \& Roepstorff 2009) It is in virtue of this participation in cultural practices, that the individuals that make up those practices come to have difference in neural (both structural and functional) patterning. This is downward causation in operation.

\section{A tension in mainstream extended cognition}

I now turn to consider the second argument of this paper: that defenders of EC should avoid using the relation of supervenience unconditionally. I want to begin this section by asking what the relation of supervenience is doing for EC. As mentioned in section 1.2, if one reads Clark's use of supervenience in a charitable way, one might interpret Clark's employment of supervenience to be dialectical. That is, to extend the framework of metaphysical individualism (cf. Egan 1992; Fodor 1987; Segal 1991; and others), which states that cognitive states and processes that an individual instantiates supervene on the intrinsic, physical states or processes of that individual, to include a wide supervenience base such that cognitive states and processes may (sometimes) supervene on physical states or processes crisscrossing both neural and non-neural bodily and environmental states or processes ${ }^{6}$. On the interpretation, Clark takes the framework of the metaphysical individualist and argues that this particular framework is not limited a priori to neural states and processes, but it in fact compatible with the hypothesis of extended cognition (or the extended mind). As Clark puts it in Supersizing the Mind:

\footnotetext{
${ }^{6}$ Wilson's $(1994,2004)$ account of wide computationalism advances similar claims.
} 
forces. Such factors and forces may be wholly internal to the system or may include selected elements of sensibly be considered, given the right additional circumstances, as among the physical vehicles of specific dispositional beliefs. This occurs if the traces become poised for the control of action in roughly [...] the same kind of way as internal memory traces, yielding an extended supervenience base for the agent's dispositional [...] beliefs." (2008, p. 76; italics added)

Or, as Clark summarizes the position of extended cognition later in Supersizing the Mind:

\begin{abstract}
"A recurrent theme in previous chapters has been the ability of body and world to act as what might now be dubbed "participant machinery" - that is, to form part of the very machinery by means of which mind and cognition are physically realized and hence to form part of the local material supervenience base for various mental states and processes.” (2008, p. 207; italics added)
\end{abstract}

Interestingly, in contrast to supervenience, Clark also has his eye on complex systems theory (applied to cognitive science, in particular) in articulating an understanding of how complex behavior emerges from a mutually modulatory dance between processes and their activity, some of which may include processual elements in the non-neural body and environment of an individual. Note the difference in these two explanatory strategies. The first advances EC through supervenience (a dialectical strategy, perhaps?), thereby enforcing the view of cognition as continuously emerging through spatio-temporally extended loops across neural, bodily, and worldly processes and sub-processes into a fully synchronic framework. The other explanatory strategy, driven by insight from nonlinear dynamics, emphasizes the concept of ontologically diachronic emergence, and makes the case for EC by considering how the "nervous system, the body, and the environment are each rich, complicated, highly structured dynamical systems, which are coupled to one another, and [cognition] emerges from the interactions of all three systems." (Chiel \& Beer 1997, p. 554) Consider how Clark defines his preferred conception of emergence:

"the idea is to depict emergence as the process by which complex, cyclic interactions give rise to stable and salient patterns of systemic behavior. [...]. [P]henomena that depend on multiple, nonlinear, temporally asynchronous, positive feedback involving interactions will count as strongly emergent. [...]. Emergent phenomena, thus defined, will [...] reward understanding in terms of the changing values of a collective variable - a variable that tracks the pattern resulting from the interactions of multiple factors and 
“Clark \& Chalmers' (1998) aim was to show that external traces (pencil marks in a notebook) may the external environment." (2001, pp. 115-116)

Either Clark uses supervenience as a matter of dialectics (to show that the metaphysical model of individualism can be extended to fits with the picture of EC) or Clark intends to use supervenience to drive a metaphysical argument for EC. This leaves Clark with two choices: (1) give up the relation of supervenience entirely, since the relation of ontological diachronic emergence makes supervenience unsustainable simpliciter; (2) holds on to the supervenience relation, but only for dialectical purposes, thus rendering the use of supervenience talk purely terminology and metaphysically vacuous. As I have argued in this chapter, supervenience is neither a helpful scientific nor philosophical concept by which to capture dynamical systems. According to Mitchell: "If we take a snap-shot view of the higher and lower levels, then the dynamics of how the higher level is constituted and stabilized is lost. Contemporary sciences show us that there are processes, often involving negative and positive feedback or self-organization, that are responsible for generating higher-level stable properties, an these processes are not captured by a static mapping." (2012, p. 177) Another reason, I have argued, for not endorsing supervenience is that ontologically diachronic emergence entails the failure of partwhole reductionism, and therefore the failure of mereological supervenience. Consequently, defenders of EC, including Clark, should give up their endorsement of the supervenience relation, since the view of ontologically diachronic emergence I have presented here undermines supervenience per se. Indeed, what is required to make sense of time continuous dynamical systems is an account of emergence that is ontological and diachronic, since such an account can accommodate processes of reciprocal as well as mutually modulatory influence in real time.

\section{Conclusion}

In this paper, I have explored one of the less-visited (albeit the visitors are increasing) regions in the debate about emergence. Overall I have both argued and shown that it is possible to develop an account of ontological emergence that is ineliminably diachronic. Against the standard account of emergence as a supervenience relation, I have argued that what such an account of emergence misses entirely is the dynamics of how higher-level emergent phenomena are constituted and maintained as they unfold over time. This includes self-organizing and nonlinear dynamics, on the one hand, and downward causation, 
forces. Such factors and forces may be wholly internal to the system or may include selected elements of on the other. Moreover, I have used the framework of ontologically diachronic emergence to identify and discuss a tension in some of the mainstream literature over the hypothesis of extended cognition, suggesting that fans of extended cognition should give up supervenience talk unconditionally.

\section{References}

Beer, R (1995). A dynamical systems perspective on agent-environment interaction. Artificial Intelligence, $72,173-215$.

Bedau, M. (1997). Weak emergence. Philosophical Perspectives, 11, 375-399.

Belyaev, V. B., Motovilov, A. K., Sermyagin, A. V., Kuznetzov, I. V., Sobolev, Yu. G., Smolnikov, A., Klimenko, A. A., Osetrov, S. B., and Vasilev, S. I. (2001). Search for nuclear reactions in water molecules. Physics Letters B, 552(3-4), 222-226.

Bennett, K. (2011). Construction area (no hard hat required). Philosophical Studies, 154, 79-104.

Bennett, K. (2004). Global supervenience and dependence. Philosophy and Phenomenological Research, 68(3), 501-529.

Boogerd, F. C., Bruggeman, F. J., Richardson, A., Stephan, A., \& Westerhoff, H. (2005). Emergence and its place in nature: A case study of biochemical networks. Synthese, 145, 131-164.

Broad, C. D. (1925). The Mind and its Place in Nature. London: Routledge \& Paul Kegan.

Brooks, R. (1999). Cambrian Intelligence. Cambridge, MA: The MIT Press.

Clark, A. (2008). Supersizing the Mind: Embodiment, Action, and Cognitive Extension. Oxford: Oxford University.

Clark, A. (2001). Mindware. New York \& Oxford: Oxford University Press.

Clark, A. (1997). Being There. Cambridge, MA: The MIT Press.

Campbell, R. J., \& Bickhard, M. (2011). Physicalism, emergence and downward causation. Axiomathes, 21, 33-56.

Couzin, I. D., \& Krause, J. (2003). Self-organization and collective behavior in vertebrates. Advances in the Study of Behavior, 33, 1-75.

Craver, C. F., \& Bechtel, W. (2007). Top-down causation without top-down causes. Biology and Philosophy, 22, 547-563.

Di Paolo, E. (2009). Extended life. Topoi, 28, 9-21. 
Egan, F. (1992). Individualism, computation, and perceptual content. Mind, 101, 443-459.

Fodor, J. (1987). Psychosemantics. Cambridge, MA: The MIT Press.

Griffiths, P., \& Stotz, K. (2000). How the mind grows: A developmental perspective on the biology of cognition. Synthese, 122, 29-51.

Helbing, D., Schweitzer, F., Keltsch, J., \& Molnar, P. (1997a). Active walker model for the formation of human and animal trail systems. Phys. Rev. E, 56, 2527-2539.

Helbing, D., Keltsch, J., and Molna' r, P. (1997b). Modelling the evolution of human trail systems. Nature 388, 47-50

Hofweber, T., \& Velleman, D. (2010). How to endure. The Philosophical Quarterly, July, 1-21.

Humphreys, P. (2008). Synchronic and diachronic emergence. Minds \& Machines, 18, 431-442.

Humphreys, P. (1997). Emergence, not supervenience. Philosophy of Science, 64, 337-345.

Hutchins, E. (1995). Cognition in the Wild. Cambridge: The MIT Press.

Kelso, S. (1995). Dynamic Patterns. Cambridge, MA: The MIT Press.

Kim, J. (2006). Emergence: Core ideas and issues. Synthese, 151, 547-559.

Kim, J. (1999). Making sense of emergence. Philosophical Studies, 95, 3-36.

Kim, J. (1993). Supervenience and Mind. Cambridge: Cambridge University Press.

Kim, J. (1987). Strong and global supervenience revisited. Reprinted (1993) in Supervenience and Mind (pp. 79-91), Cambridge: Cambridge University Press.

Kim, J. (1984). Concepts of supervenience. Reprinted (1993) in Supervenience and Mind (pp. 53-78), Cambridge: Cambridge University Press.

Ladyman, J., \& Ross, D. (2007). Every Thing Must Go: Metaphysics Naturalized. Oxford and New York: Oxford University Press.

Laland, K. N. (2004). Extending the extended phenotype. Biology and Philosophy, 19, 313-325.

Lewis, D. (1983). Extrinsic properties. Philosophical Studies, 44, 197-200.

McLaughlin, B., \& Bennett, K. (2011). Supervenience. Stanford Encyclopedia of Philosophy, http://plato.stanford.edu/entries/supervenience/

McLaughlin, B. (1997). Emergence and supervenience. Intellectica, 25, 25-43.

Menary, R. (2007). Cognitive Integration: Mind and Cognition Unbounded. Basingstoke: Palgrave Macmillan.

Mitchell, S. (2012). Emergence: logical, functional and dynamical. Synthese, 185, 171-186. 
O’Connor, T., \& Wong, H. Y. (2012). Emergent properties. In Stanford Online Encyclopedia of Philosophy. Retrieved from http://plato.stanford.edu/entries/ properties-emergent/O'Connor, T., \& Wong, H. Y. (2005). The metaphysics of emergence Nous, 39, 658-678. O’Connor, T.

(2000). Causality, mind, and free will. Philosophical Perspectives, 14, 105-117.

Odling-Smee, F. J. (1988). Niche constructing phenotypes. In H. C. Plotkin (ed.), The Role of Behavior in Evolution (pp. 73-132), Cambridge, MA: The MIT Press.

Oyama, S., Griffiths, P., \& Gray, R. (2001). Introduction: What is developmental systems theory? In. S. Oyama, P. Griffiths, and R. Gray (eds.), Cycles of Contingency: Developmental Systems and Evolution (pp. 1-11). Cambridge, MA: The MIT Press.

Oyama, S. (2001). Terms in tension: What do you do when all the good words are taken? In. S. Oyama, P. Griffiths, and R. Gray (eds.), Cycles of Contingency: Developmental Systems and Evolution (pp. 177-194). Cambridge, MA: The MIT Press.

Pfeifer, R., Lida, F., \& Bongard, J. (2005). New robotics: Design principles for intelligent systems. Artificial Life, 11, 99.120.

Schewe, P. F., Stein, B., Riordon, J. (2003). A water molecule's chemical formula is really not $\mathrm{H}_{2} \mathrm{O}$. Physics News Update (The American Institute of Physics Bulletin of Physics News), 648 (July 31).

Seeley, T. (1989). Social foraging in honey bees: How nectar foragers assess their colony's nutritional status. Behavioral Ecology and Sociobiology, 24, 181-199.

Segal, G. (1991). Defense of a reasonable individualism. Mind, 100, 485-494.

Seibt, J. (2009). Forms of emergent interaction in general process theory. Synthese, 166, 479-512.

Sider, T. (1999). Global supervenience and identity across times and worlds. Philosophy and Phenomenological Research, 59, 913-937.

Silberstein, M. (2012). Emergence and reduction in context: Philosophy of science and/or analytical metaphysics. Metascience, 21, 627-642.

Silberstein, M., \& McGeever, J. (1999). The search for ontological emergence. Philosophical Quarterly, 49, 182-200.

Spivey, M. (2007). The Continuity of Mind. Oxford and New York: Oxford University Press.

Stalnaker, R. (1996). Varieties of supervenience. Philosophical Perspectives, 10, 221-241.

Stephan, A. (1999). Varieties of emergentism. Evolution and Cognition, 5(1), 49-59.

Sterelny, K. (2003). Thought in a Hostile World. Malden, MA: Blackwell Publishing. 
Sutton, J. (2010). Exograms and interdisciplinarity: history, the extended mind, and the civilizing process. In R. Menary (ed.), The Extended Mind (pp. 189-225). Cambridge, MA: The MIT Press.

Theiner, G., Allen, C., \& Goldstone, R. L. (2010). Recognizing group cognition. Cognitive Systems Research, 11, 378-395.

Van Brakel, J. (2010). Chemistry and physics: No need for metaphysical glue. Foundations of Chemistry, 12, 123-136.

Van Cleve, J. (1990). Emergence vs. pansychism: Mind dust or magic? Philosophical Perspectives, 4, 215-226.

Van Gelder, T. (1998). The dynamical hypothesis in cognitive science. Behavioral and Brain Sciences, $21,615-665$.

Varela, F., Thompson, E., \& Rosch, E. (1991). The Embodied Mind. Cambridge, MA: The MIT Press. Wheeler, M. (2005). Reconstructing the Cognitive World. Cambridge, MA: The MIT Press.

Wilson, R. A., \& Clark, A. (2009). How to situate cognition: letting nature take its course. In P. Robbins \& M. Aydede (Eds.), The Cambridge Handbook of Situated Cognition (pp. 55-77). Cambridge: Cambridge University Press.

Wimsatt, W. (2000). Emergence as non-aggregative and the biases of reductionism. Foundations of Science, 5, 269-297.

Wimsatt, W. (1986). Forms of aggregativity. In A. Donagan., A.N. Perovich., and M.V. Wedin (eds.), Human Nature and Natural Knowledge (pp. 259-291). Boston: D. Reidel. 